\title{
Primary Hepatic Gastrinoma as an Unusual Manifestation of Zollinger-Ellison Syndrome
}

\author{
Hideaki Naoe $^{a}$ Hajime Iwasaki $^{\text {a }}$ Takeshi Kawasaki $^{a}$ \\ Tetsu Ozaki $^{\mathrm{a}}$ Hideharu Tsutsumi $^{\mathrm{a}}$ Ayako Okuda $^{\mathrm{a}}$ \\ Takeyasu Konoe $^{a}$ Kouichi Nonaka ${ }^{a}$ Eisuke Kaku ${ }^{a}$ \\ Takashi Shono $^{a}$ Kazunori Yokomine $^{a}$ Kouichi Sakurai $^{\mathrm{a}}$ \\ Ken-ichi lyama ${ }^{b}$ Masahiko Hirota $^{c}$ Yutaka Sasaki $^{a}$
}

Departments of a Gastroenterology and Hepatology and 'burgical Pathology, Graduate School of Medical Sciences, Kumamoto University, and 'Department of Surgery, Kumamoto Regional Medical Center, Kumamoto, Japan

\section{Key Words}

Gastrinoma Zollinger-Ellison syndrome $\cdot$ Arterial stimulation and venous sampling test

\begin{abstract}
We report a rare case of primary hepatic gastrinoma. A 77-year-old woman exhibited continuous watery diarrhea for 8 months and weight loss. Bacterial cultures of the stools were negative and colonoscopy revealed no abnormalities. Esophagogastroduodenoscopy showed severe reflux esophagitis and multiple duodenal erosions. Computed tomography and magnetic resonance imaging detected two solid masses measuring $<2 \mathrm{~cm}$ in diameter in the right lobe of the non-cirrhotic liver. Microscopically, the tumor was consistent with neuroendocrine tumor (grade 2) with abundant gastrin-immunoreactive cells. Endoscopic ultrasound detected no other alternative primary source of an endocrine tumor. The serum gastrin levels exceeded $40,000 \mathrm{pg} / \mathrm{ml}$ in the absence of $\mathrm{H}_{2}$ receptor antagonist and proton pump inhibitor administrations. Based on an arterial stimulation and venous sampling test, the patient was diagnosed as primary gastrinoma of the liver. Our findings demonstrated the presence of Zollinger-Ellison syndrome in a patient who was subsequently cured by surgical resection of the liver tumors.
\end{abstract}




\section{Introduction}

Gastrinoma-induced Zollinger-Ellison syndrome (ZES) is characterized by refractory peptic ulcers of the upper gastrointestinal tract, diarrhea and gastric acid hypersecretion associated with non-beta islet cell tumors of the pancreas [1]. Most reports suggest that the diagnosis of ZES can be established in patients with gastrin levels $>1,000 \mathrm{pg} / \mathrm{ml}$ or 10 -fold higher than standard level, associated with acid production [1-4].

More than half of all gastrinomas are sporadic, whereas approximately $18-25 \%$ are associated with multiple endocrine neoplasia type 1 (MEN-1) syndrome, which is characterized by pancreatic endocrine tumors, pituitary adenomas and parathyroid hyperplasia $[1,2,5]$. At the time of diagnosis, $50-60 \%$ of gastrinomas are malignant and associated with metastases [2]. The only way to cure patients without non-resectable metastatic disease is to perform surgery.

Gastrinomas are frequently small in size and are often difficult to find preoperatively. Selective arterial secretin or calcium stimulation with sampling from the hepatic veins is helpful for detecting the localization of gastrinomas. In this test, the diagnosis is established if a more than two-fold increase in gastrin concentration is observed in the hepatic vein after secretin/calcium injection.

Recent progress has cultivated our understanding of the molecular bases of gastrinoma. Indeed, alterations in several oncogenes including c-Myc, HER2/neu (ElbB-2) and tumor suppressor genes such as MEN-1 and P16 (INK4a) have been reported [1]. In addition, mutations in biologic factor such as growth factors and receptors have been described. However, these alterations are not absolutely correlated with aggressive biology [1]. More precise mechanisms, therefore, need to be clarified with regard to tumorigenesis of gastrinoma.

The vast majority of gastrinomas are found in the pancreas or duodenum $[3,6,7]$. Although sporadic gastrinomas not associated with MEN-1 have been reported in other locations, including the liver, these ectopic gastrinomas are rare $[1,7]$. To the best of our knowledge, less than 30 cases of primary hepatic gastrinomas have been reported in the literature $[3,7]$. In this report, we present a patient with two small primary gastrinomas in the liver, who was cured by surgical resection of the tumors. The unique feature of our case is that there were two independent small tumors in the liver, both of which were diagnosed as gastrinoma pathologically.

\section{Case Report}

A 77-year-old woman was admitted to our hospital with chief complaints of diarrhea for 8 months and a weight loss of $6 \mathrm{~kg}$. Diarrhea without blood was seen 7-10 times a day. Bacterial cultures of the stools were repeatedly negative. Colonoscopy revealed no significant abnormalities. Esophagogastroduodenoscopy showed severe erosive esophagitis ( $\underline{\mathrm{fig} .1 \mathrm{1}} \mathrm{a}$ ), erosive gastritis, and multiple ulcers that were accompanied by surrounding edema in the second portion of the duodenum (fig. 1b). Ultrasonography showed that the patient had two small hypoechoic lesions in the right lobe of the liver. A plain computed tomography (CT) scan showed two low-attenuation round lesions in the right hepatic lobe (fig. 2a). A contrast-enhanced CT scan obtained during the arterial phase demonstrated a $19 \mathrm{~mm}$ ring enhancing mass (fig. $2 \mathrm{~b}$, arrow) with washout in the delayed phase (fig. 2c, arrow) in the subcapsular lesion of the right hepatic lobe, and a $16 \mathrm{~mm}$ faintly enhancing mass (fig. $2 \mathrm{~d}$, arrowhead) 
with washout in the delayed phase (fig. 2e, arrowhead) within the posterior segment of the right hepatic lobe. Magnetic resonance imaging (MRI) confirmed the CT findings of masses in the liver and additionally showed a normal pancreas and no evidence of tumors at any other sites (fig. 2f). Endoscopic ultrasound also revealed no tumors in the pancreas and the duodenal wall (data not shown). Transcutaneous tumor biopsy can be used to identify the type of liver tumor that is present. Our pathological examination found there was a solid growth of uniform middle-sized neuroendocrine tumor cells (grade 2) with eosinophilic granules (ig. $3 \mathrm{a}$ ). Immunohistochemically, the tumor cells were positive for gastrin (fig. 3a, inset) and negative for insulin, VIP, glucagon, somatostatin and somatostatin receptors (data not shown). The MIB-1 labeling index of this tumor was approximately $20 \%$ (fig. 3b). The serum gastrin level was checked upon admission and determined to be $41,000 \mathrm{pg} / \mathrm{ml}$.

As the patient was not receiving any acid-suppressive medication when first examined, we initially suspected the presence of gastrinoma in the duodenum or pancreas, with metastasis to the liver. However, since there was no evidence of gastrinoma in the pancreas or the duodenal wall, we attempted to detect the site of the gastrinoma by using arterial stimulation and venous sampling (ASVS) tests. Proper hepatic artery, dorsal pancreatic artery, gastroduodenal artery, splenic artery and superior mesenteric artery were selectively catheterized for stimulation by rapid injection of calcium gluconate. Blood was sampled through the hepatic vein before as well as 30, 60, 90, 120 and $180 \mathrm{~s}$ after calcium gluconate injection. All hepatic vein samples showed equally high gastrin levels (table 1). These results suggested that the primary gastrinoma might be the two small tumors that were observed in the liver.

To exclude MEN-1, brain MRI and thyroid ultrasonography was performed. However, no apparent abnormalities were detected in either the pituitary or the parathyroid glands. In addition, FDG PET showed no abnormal uptake in the liver or at any other site. Finally, a right lateral segmentectomy of the liver was performed to remove the liver tumors. In line with our preoperative diagnosis, the pathological examination revealed two gastrinomas in the right lobe of the liver.

Twelve months after the operation, the patient remains asymptomatic and her serum gastrin levels are within the normal range. These findings are consistent with a surgical cure of ZES.

\section{Discussion}

In 1955, Zollinger and Ellison described a syndrome characterized by ulceration of the upper jejunum, hypersecretion of gastric acid and non-beta islet cell tumors of the pancreas [8]. Similar to that seen in our current case, diarrhea has been shown to be one of the most common symptoms, with its presence documented in $>70 \%$ of patients. Gastric acid hypersecretion may cause direct intestinal mucosal injury and inactivation of pancreatic enzymes, which results in diarrhea [7]. Additionally, patients rarely present with only one symptom. While weight loss with abdominal pain and diarrhea are important symptoms that suggest the presence of gastrinoma, it is difficult to diagnose ZES initially, as the mean delay from onset to diagnosis has been reported to be 5-6 years [1, 6, 9]. Of 261 ZES patients treated at the National Institutes of Health, 98\% were misdiagnosed prior to establishing a final diagnosis of ZES [9]. Unfortunately, the diagnosis of ZES is becoming more difficult due to the widespread use of proton pump inhibitors (PPIs) as the symptoms can be masked by long-term treatment with PPIs [1]. In fact, it was shown that when patients were being treated with either PPIs or $\mathrm{H}_{2}$ receptor antagonists, it was not possible to make a gastrinoma diagnosis based on the fasting plasma gastrin levels [2].

In contrast, selective arterial secretin or calcium stimulation with sampling from the hepatic veins is helpful in detecting the localization of the gastrinoma $[4,10]$. Since these compounds stimulate the release of gastrin by the gastrinoma tumor cells, 
patients with gastrinomas show a rapid rise in the serum gastrin level in response to the administration of secretin or calcium [1]. When we performed an ASVS test for the current case, we were unable to detect any significant changes in the serum gastrin levels, with the gastrin levels of all samples taken from the hepatic vein found to be equally extremely high. Thus, these observations suggested that the gastrinoma was potentially located in the liver. It has been previously shown that gastrinomas arise in the so-called 'gastrinoma triangle', which is defined by the junction of the cystic duct and common bile duct, the junction of the second and third portions of the duodenum, and the junction between the neck and body of the pancreas [1,2].

However, ectopic gastrinomas that occur outside of the gastrinoma triangle are rare, with $<30$ primary hepatic gastrinomas having been reported in the literature $[3,7]$. In the NIH study, primary hepatic gastrinomas occurred in $<2 \%$ of the ZES patients [9]. Although most gastrinomas grow slowly, 60-90\% of these gastrinomas are malignant, with $25 \%$ showing rapid growth $[1,2,5]$. Therefore, the only way to cure these patients is to perform surgery, which needs to be considered in all patients without MEN-1, provided the tumor is resectable.

In conclusion, we report a rare case of primary hepatic gastrinoma. Evaluation of the patient using preoperative image diagnosis and an ASVS test led to surgical excision of the tumors and cure of the patient.

Table 1. Serum gastrin levels $(\mathrm{pg} / \mathrm{ml})$ before and after calcium injection

\begin{tabular}{|c|c|c|c|c|c|c|}
\hline \multirow{2}{*}{$\begin{array}{l}\text { Calcium } \\
\text { injection site }\end{array}$} & \multicolumn{6}{|c|}{ Time, min } \\
\hline & 0 & 30 & 60 & 90 & 120 & 180 \\
\hline PHA & 36,000 & 41,000 & 40,000 & 37,000 & 39,000 & 40,000 \\
\hline DPA & 45,000 & 43,000 & 39,000 & 46,000 & 41,000 & 44,000 \\
\hline GDA & 45,000 & 49,000 & 41,000 & 42,000 & 45,000 & 46,000 \\
\hline SA & 46,000 & 39,000 & 40,000 & 42,000 & 41,000 & 39,000 \\
\hline SMA & 41,000 & 38,000 & 39,000 & 39,000 & 38,000 & 38,000 \\
\hline
\end{tabular}

Gastrin concentrations were measured in the hepatic vein after calcium gluconate injection directly into the respective arteries. PHA = Proper hepatic artery; DPA = dorsal pancreatic artery; GDA = gastroduodenal artery; SA = splenic artery; SMA = superior mesenteric artery. 

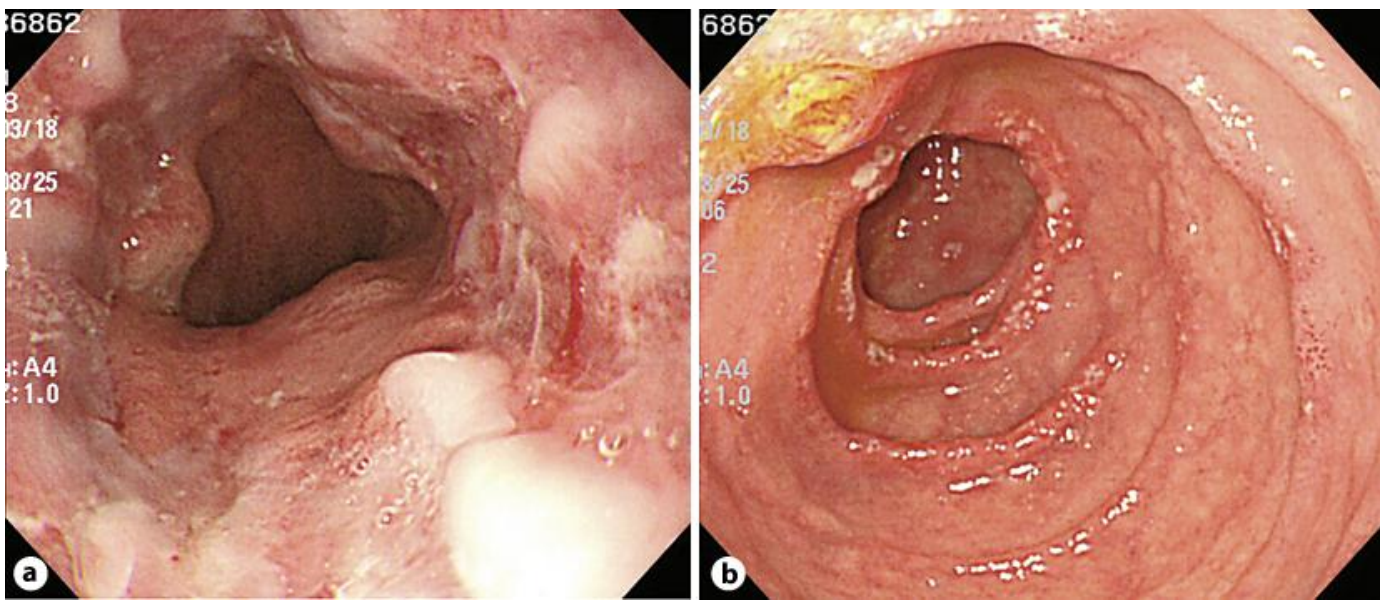

Fig. 1. Esophagogastroduodenoscopy showing severe erosive esophagitis and duodenitis.

a Circumferential reflux esophagitis with superficial ulceration was observed in the distal esophagus near the gastroesophageal junction. $\mathbf{b}$ Multiple erosions with surrounding edema were found in the second portion of the duodenum.
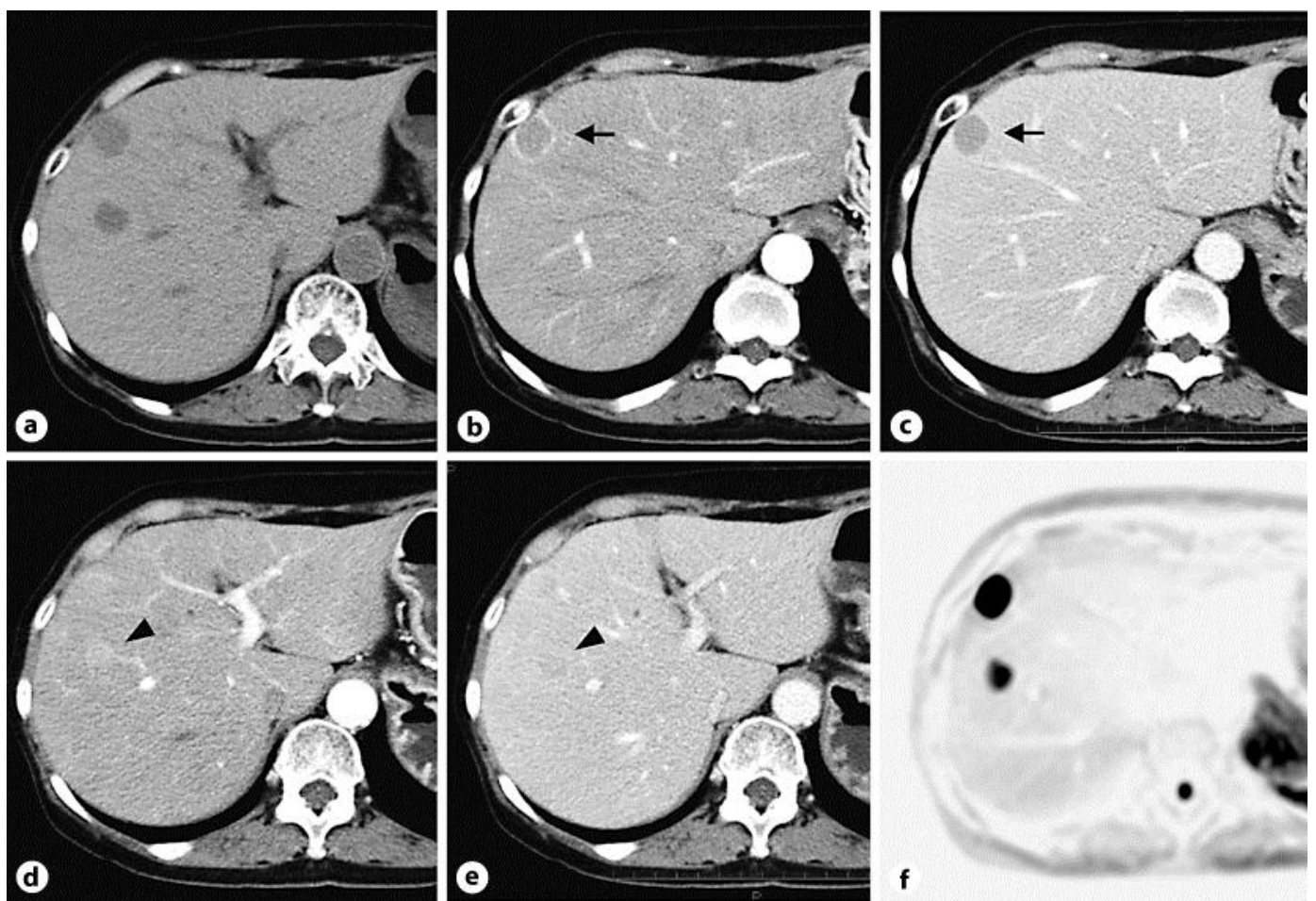

Fig. 2. Diagnostic imaging showing two masses in the right hepatic lobe. a A plain CT scan of the abdomen revealed two low-attenuation round lesions in the right hepatic lobe. A contrast-enhanced CT scan showed a $19 \mathrm{~mm}$ ring enhancement (b, arrow) in the arterial phase with washout in the delayed phase (c, arrow) within the subcapsular lesion. A $16 \mathrm{~mm}$ faintly enhancing mass (d, arrowhead) in the arterial phase with washout in the delayed phase (e, arrowhead) was seen within the posterior segment of the right hepatic lobe. The high signals seen for the tumors on the diffusion-weighted MR image are consistent with diffusion restriction (f). 


\begin{tabular}{r|l|l|l}
$\begin{array}{r}\text { Case Reports in } \\
\text { Gastroenterology }\end{array}$ & $\begin{array}{l}\text { Case Rep Gastroenterol 2012;6:590-595 } \\
\text { DOI: 10.1159/000343157 }\end{array}$ & $\begin{array}{l}\text { Published online: } \\
\text { September 18, 2012 }\end{array}$ & $\begin{array}{l}\text { @ 2012 S. Karger AG, Basel } \\
\text { ISSN 1662-0631 } \\
\text { www.karger.com/crg }\end{array}$ \\
\hline
\end{tabular}

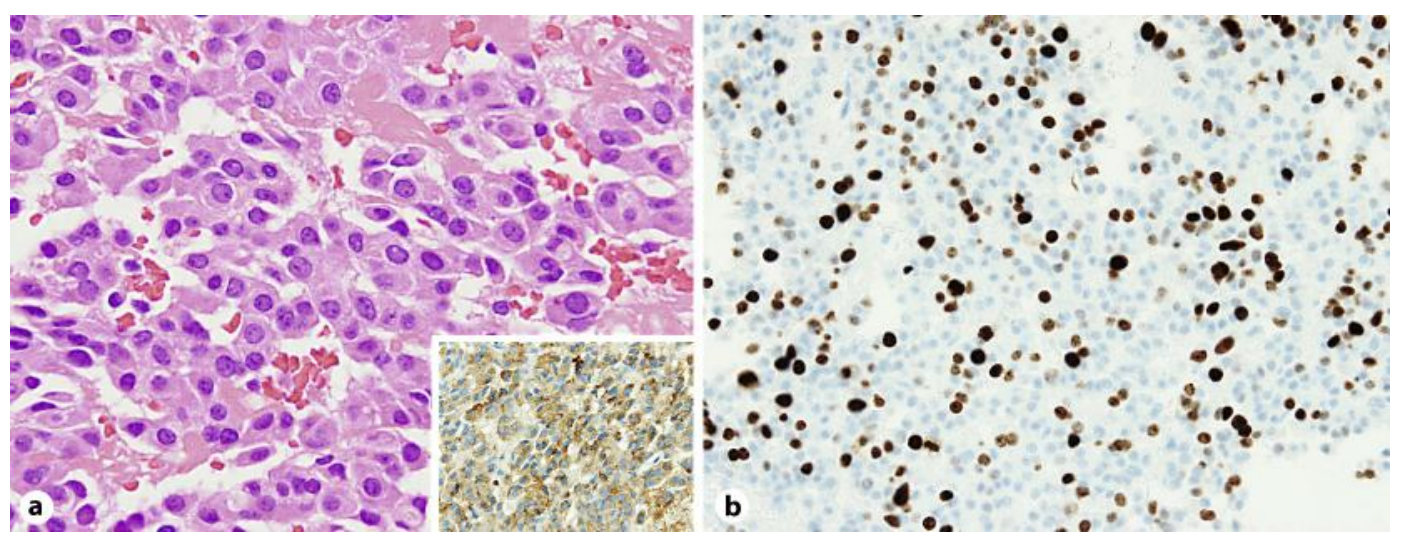

Fig. 3. Pathological and immunohistochemical findings consistent with gastrinoma. a Pathological findings showed a neuroendocrine tumor consistent with gastrinoma. Stains are positive for gastrin (inset). b MIB-1 labeling index of this tumor was approximately $20 \%$.

\section{References}

1 Ellison EC, Johnson JA: The Zollinger-Ellison syndrome: a comprehensive review of historical, scientific, and clinical considerations. Curr Probl Surg 2009;46:13-106.

-2 Fendrich V, Langer P, Waldmann J, Bartsch DK, Rothmund M: Management of sporadic and multiple endocrine neoplasia type 1 gastrinomas. Br J Surg 2007;94:1331-1341.

3 Ito T, Jensen RT: Primary hepatic gastrinoma: an unusual case of Zollinger-Ellison syndrome. Gastroenterol Hepatol (N Y) 2010;6:57-59.

-4 Turner JJ, Wren AM, Jackson JE, Thakker RV, Meeran K: Localization of gastrinomas by selective intra-arterial calcium injection. Clin Endocrinol (Oxf) 2002;57:821-825.

-5 Norton JA, Fraker DL, Alexander HR, Venzon DJ, Doppman JL, Serrano J, Goebel SU, Peghini PL, Roy PK, Gibril F, Jensen RT: Surgery to cure the Zollinger-Ellison syndrome. N Engl J Med 1999;341:635-644.

6 Wu PC, Alexander HR, Bartlett DL, Doppman JL, Fraker DL, Norton JA, Gibril F, Fogt F, Jensen RT: A prospective analysis of the frequency, location, and curability of ectopic (nonpancreaticoduodenal, nonnodal) gastrinoma. Surgery 1997;122:1176-1182.

7 Evans JT, Nickles S, Hoffman BJ: Primary hepatic gastrinoma: an unusual case of Zollinger-Ellison syndrome. Gastroenterol Hepatol (N Y) 2010;6:53-56.

8 Zollinger RM, Ellison EH: Primary peptic ulcerations of the jejunum associated with islet cell tumors of the pancreas. Ann Surg 1955;142:709-723; discussion 724-728.

-9 Roy PK, Venzon DJ, Shojamanesh H, Abou-Saif A, Peghini P, Doppman JL, Gibril F, Jensen RT: ZollingerEllison syndrome. Clinical presentation in 261 patients. Medicine (Baltimore) 2000;79:379-411.

10 Imamura M, Takahashi K, Adachi H, Minematsu S, Shimada Y, Naito M, Suzuki T, Tobe T, Azuma T: Usefulness of selective arterial secretin injection test for localization of gastrinoma in the ZollingerEllison syndrome. Ann Surg 1987;205:230-239. 